\title{
La Arqueología en las Universidades españolas
}

\author{
M. Ángeles Querol \\ Departamento de Prehistoria \\ Universidad Complutense \\ Madrid
}

La Arqueología no es una profesión titulada. Eso significa que no existe hasta este momento ninguna posibilidad de que una persona que desee dedicarse profesionalmente a la Arqueología se acoja al Art. 26 de la Constitución que habla de las profesiones tituladas, del derecho que les asiste a tener colegios, estatutos y normas propias. La Arqueología no tiene por lo tanto un respaldo social claro, nadie sabe muy bien qué es eso ni quiénes son o qué deben saber las personas que a ello se dedican.

Entre la afición, el hobby, el diletantismo y las confusiones, la Universidad española, principal responsable de este estado de la cuestión, ha ido por caminos bastante originales durante este siglo. Por una cuestión histórica, la Arqueología se identificó tempranamente con la Historia del Arte del mundo clásico y muchas generaciones -la mía, por ejemplofuimos formadas en esa idea. El contraste entre tal concepción y la otra -la Arqueología concebida como ciencia de la reconstrucción o representación de las culturas del pasado basada en el estudio de sus restossupuso la división del mundo universitario en bandos aparentemente irreconciliables cuyas características, como veremos, se reflejan en las ofertas, las denominaciones y los contenidos de las asignaturas.

Hoy la situación, sin dejar de ser prometedora, es anárquica y algo extraña; por primera vez en nuestra historia existe una Universidad -la Rovira i Virgili, de Tarragona- que ofrece un título propio de Arqueología -Graduado superior en Arqueología, ya que la licenciatura no existe al no estar homologada por el Ministerio-; también por primera vez, en los nuevos planes de estudio de la titulación de Historia se incluye como troncal de segundo ciclo -es decir, obligatoria para todo el mundo que estudie Historia- una asignatura titulada "Arqueología general", que el B.O.E. define como "Método del conocimiento histórico en sus diversos aspectos".

Y también por primera vez las Facultades de Historia o de Humanidades han podido inventarse y ofrecer un buen número de asignaturas optativas con títulos y contenidos variados y casi siempre motivados por las especializaciones de los miembros del profesorado o bien, en los mejores casos, por las demandas de la ciencia moderna o de la sociedad.

Estas cuestiones dibujan un paisaje nuevo y variado en nuestras Universidades y en las enseñanzas denominadas "Arqueología" en el que no se encuentra casi nada homogéneo y que merece la pena revisar con cierto detalle para comprender no sólo el punto en el que nos encontramos sino, sobre todo, los posibles caminos de futuro.

En los últimos meses he conseguido reunir información sobre asignaturas que incluyen en su denominación la palabra "Arqueología" o el adjetivo "Arqueológico/a", procedentes de 10 Universidades. Es cierto que existen muchas otras asignaturas que, sin incluir esa palabra en su denominación, lo que explican es Arqueología -aunque depende, claro está, de lo que se entienda por ésta-. Pero necesitaba una razón, aunque fuera artificial, para seleccionar la muestra. Con esta información he elaborado este pequeño artículo en el que intentaré dar una visión de qué es lo que se está enseñando cuando se enseña Arqueología. En definitiva, lo que me preocupa: cuál es la concepción que se está trasmitiendo a las generaciones actuales sobre esta ciencia.

\section{ASIGNATURAS ANALIZADAS, POR ORDEN ALFABÉTICO}

\section{Actuación sobre el Patrimonio Arqueológico} (La Rioja) (2)

Arqueología (Castilla-La Mancha) (2)

Arqueología (La Rioja) (2)

Arqueología (Las Palmas) (2)

Arqueología (Valencia) (2)

Arqueología clásica (Santiago) (I)

Arqueología clásica (Valencia) (2)

Arqueología clásica (Valladolid) (I) 
Arqueología de Gallaecia (Santiago) (I)

Arqueología de la antiguedad tardía (Valladolid) (?)

Arqueología de la cultura ibérica (Jaén) (I)

Arqueología de la Península Ibérica

(Valladolid) (?)

Arqueología de la Península lbérica durante el I milenio a C. (Granada) (I/2)

Arqueología de las colonizaciones en la Península Ibérica (Valladolid) (?)

Arqueología de las mujeres (Aut.Barna) (2)

Arqueología de las sociedades agrícolas (Aut.Barna) (2)

Arqueología de las sociedades cazadorasrecolectoras (Aut.Barna) (2)

Arqueología de los animales (Valencia) (2)

Arqueología de los asentamientos clásicos (Aut.Barna) (I)

Arqueología de los asentamientos prehistóricos (Aut.Barna) (2)

Arqueología de Mesoamérica (Complutense) (I)

Arqueología de Oriente (Valladolid) (3)

Arqueología del Área Andina

(Complutense) (I)

Arqueología del Cuaternario

(Complutense) (2)

Arqueología del Mar (Valencia) (2)

Arqueología del origen del estado (Aut.Barna) (2)

Arqueología del Paisaje (Valencia) (2)

Arqueología del Pleistoceno en la Península Ibérica (Valladolid) (?)

Arqueología del Próximo Oriente (Granada) (I)

Arqueología del territorio (Granada) (2)

Arqueología del territorio (Jaén) (2)

Arqueología experimental (Jaén) (2)

Arqueología experimental y Etnoarqueología (Granada) (2)

Arqueología fenicio-púnica (Valencia) (2)

Arqueología general (Aut.Barna) (2)
Arqueología general (Aut.Barna) (I)

Arqueología General (Complutense) (I)

Arqueología General (Valladolid) (2)

Arqueología griega (Valladolid) (I)

Arqueología hispánica (Aut.Barna) (I)

Arqueología I (Granada) (2)

Arqueología ibérica (Valencia) (2)

Arqueología islámica (Jaén) (I)

Arqueología medieval (Aut.Barna) (2)

Arqueología medieval (Granada) (2)

Arqueología medieval de los reinos cristianos (Jaén) (I)

Arqueología Prehistórica

(Complutense) (2)

Arqueología protohistórica del Mediterráneo (Santiago) (I)

Arqueología romana (Aut.Barna) (I)

Arqueología romana (Valladolid) (?)

Arqueología urbana (Jaén) (2)

Arqueometría (Granada) (2)

Arqueozoología (Jaén) (2)

Concepto de Prehistoria y Arqueología (Granada) (0)

Conservación del patrimonio arqueológico (Granada) (2)

Didáctica, gestión y política de la Arqueología (Aut.Barna) (2)

Documentación en Arqueología

(Valladolid) (?)

Etnoarqueología (Complutense) (2)

Excavación arqueológica y laboratorio (Jaén) (2)

Gestión del Patrimonio Arqueológico (Complutense) (2)

Gestión y Museística en Arqueología (Jaén) (2)

Introd. a la Arqueología del mundo medieval, moderno y contemp. (Valencia) (2)

Introducción a la Arqueología (Aut. Barna) (2)

Introducción a la Arqueología (Aut.Barna) (I)
Introducción a la Arqueología (Valencia) (2)

Introducción a la Arqueología del Próximo Oriente (Valencia) (2)

Introducción a la metodología en Arqueología Prehistórica (Valencia) (2)

Introducción a la restauración arqueológica (Jaén) (2)

La intervención y conservación del Patrimonio Arqueológico (Valencia) (2)

Método arqueológico (Las Palmas) (2)

Métodos cuantitativos aplicados a la Prehistoria y a la Arqueología (Granada) (2)

Métodos de la Arqueología de campo (Granada) (2)

Prácticas en Arqueología pre y proto histórica (Jaén) (2)

Técnicas y procedimientos de la investigación en Arqueología (Valencia) (2)

Esto hace un total de 74 títulos para las 10 Universidades. El reparto es el siguiente:

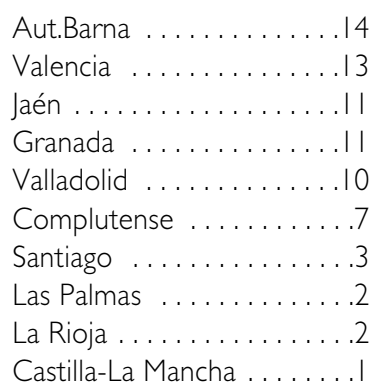

Es cierto que la situación de cada una de estas Universidades es distinta. Así, por ejemplo, algunas incluyen estas asignaturas en la titulación de Humanidades (Jaén, La Rioja y CastillaLa Mancha), mientras que el resto lo hacen en la de Historia. De estas últimas, algunas tienen un itinerario denominado "Prehistoria" (Complutense, Valladolid, Autónoma de Barcelona), mientras que el resto no lo tienen. Todos estos datos, junto a la cantidad de profesorado de cada centro, motivan las fuertes variaciones que observamos.

\section{CÓMO SE CONCIBE LA ARQUEOLOGÍA}

Estudiando el contenido de los programas de estas asignaturas, se observa una división bastante real en tres tipos: 


\section{I. "ARQUeOlogía como objetos".}

Obedece a una concepción normativista de la Historia, en la que lo que importa son los hechos concretos (o los objetos concretos), su descripción, su identificación y su seriación o cronología. Para la orientación más clásica esos objetos han de ser, además, de carácter artístico (es decir, ser bonitos, vistosos y valiosos, con toda la carga de moda y subjetividad que eso conlleva). Para la concepción más avanzada, incluye, además de lo artístico, objetos que no lo son y ciertas tecnologías: urbanismo, arquitectura, cerámicas, formas de enterramiento, etc. En la jerga arqueológica moderna este grupo de cosas suele titularse "cultura material". Es cierto que esta expresión ha pasado a formar parte de la bibliografía actual de forma indiscutible, pero en mi opinión, y de acuerdo con algunas de mis publicaciones, resulta a veces muy reduccionista: la expresión "cultura" es demasiado compleja para aplicarla a un montón de cosas sueltas o de objetos a menudo descontextualizados. Como mucho, a este montón yo le llamaría "algunos objetos materiales de cultura".

Las asignaturas que hemos analizado y que se ajustan a este modelo llevan detrás el número I y se caracterizan porque sus denominaciones incluyen o suelen incluir referencias geográficas (Arqueología de Grecia, Arqueología de Roma, etc.)

El número de asignaturas de las que he podido analizar el programa son 68 (hay 6 de la Universidad de Valladolid que no he visto). De ellas hay 15 de este tipo I, lo que representa un 22\%. En 10 de éstas he podido saber qué Área de conocimiento se ocupa de la docencia: en 8 casos es el Área de Arqueología (80\%), y 2 el Área de Historia de América. No hay ninguna del área de Prehistoria.

\section{EJEMPLO DE TEMARIO I impartido por el Área de Arqueología.}

\section{"Arqueología Clásica". Obligatoria para Historia de la Universidad de Santiago de Compostela}

I. El mundo griego. Desarrollo y estado actual de la investigación.

2. El mundo Egeo en el II milenio. Principales manifestaciones.

3. El mundo arcaico. Aspectos generales y fases. Estatuaria y Relieves.
4. El periodo clásico. Arquitectura civil y urbanismo.

5. El periodo clásico. Escultura, relieves funerarios y retratos.

6. El periodo clásico. Cerámica y pintura en época severa.

7. La época helenística. Arquitectura religiosa y civil. Necrópolis.

8. La época helenística. Escultura y retrato.

9. La época helenística. Pintura, Mosaicos, Cerámica.

10. Itálica desde la Edad del Hierro hasta el siglo V: griegos, etruscos.

II. Roma protourbana. Arquitectura, pintura, escultura, cerámica.

12. Roma tardorepublicana. Arquitectura, mosaico, pintura, cerámica.

13. La época de Augusto. Arquitectura, escultura, pintura, artes menores.

14. La época Julio-Claudia y Flavia. Arquitectura, escultura, relieve, pintura.

15. El siglo II. Arquitectura y urbanismo. Mundo funerario.

16. El siglo III. Escultura, relieve, retrato y estatuaria.

17. El siglo II. Pintura, mosaico, artes menores e industriales.

18. La época de los Severos. Arquitectura, escultura, retrato, relieve, pintura.

19. La época de la tetrarquía. Arquitectura y urbanismo, escultura, retrato.

20. La época de Constantino hasta Justiniano. Arquitectura, retrato,escultura.

\section{2. "ARQUEOLOGÍA COMO CIENCIA".}

Obedece a una idea muy distinta: la Arqueología es la ciencia que reconstruye el pasado -para unas personas, este pasado son objetos, para otras, son procesos-. Tiene un método -o más de uno- y un buen número de procedimientos técnicos, como cualquier otra ciencia. Como es la misma ciencia se aplique al mundo clásico, al medieval o al prehistórico, soporta muy mal las atribuciones geográficas o cronológicas.

Las asignaturas que aquí se incluyen y que se ajustan a este modelo llevan el número 2. De nuestro total (68), hay 49 de este tipo (72\%). De esas 49 sólo conocemos el Área de conocimiento a la que se adscriben en 25 casos: 13 a la de Prehistoria (52\%), 4 a ambas áreas, compartiendo asignatura; 7 a Arqueología y I a Historia Medieval.

\section{EJEMPLO DE TEMARIO 2, impartido por el Área de Prehistoria}

\section{"Arqueología". Obligatoria de la titulación de Humanidades en Castilla-La Mancha}

I. Historiografía de la Arqueología.

2. El registro arqueológico.

3. Localización y recuperación del registro arqueológico.

4. La medida del tiempo. Sistemas de datación.

5. El marco ambiental.

6. Antropología física.

7. Arqueometría.

8. Arqueología social.

9. Arqueología cognitiva. El análisis de los símbolos.

10. Interpretación en Arqueología.

\section{EJEMPLO DE TEMARIO 2, impartido por el Área de Arqueología}

\section{"Arqueología I o general". Obligatoria de la titulación de Historia . Universidad de Granada}

I. Concepto de Arqueología

2. Historia de las investigaciones arqueológicas

3. Los restos de la cultura material. Las fuentes escritas

4. Introducción a la Arqueología de campo

5. Introducción a la Arqueometría

6. Análisis social a partir de la Arqueología 
Además de estos dos grupos, que diseñan perfectamente nuestra histórica división, encontramos otro tipo, muy poco representado:

\section{3. "ARQUEOLOGÍA COMO HISTORIA".}

Sus temarios son idénticos a los de la Historia y no alcanzamos a comprender bien su naturaleza de Arqueología, es decir, por qué les han puesto esta denominación. En algunas ocasiones se unen a la concepción de Arqueología como objetos, por lo que se convierte en una Arqueología como historia con objetos. Las he distinguido con el número 3 y sólo he encontrado I, adscrita al Área de Arqueología.

\section{EJEMPLO DE TEMARIO 3, impartido por el Área de Arqueología}

"Arqueología de Oriente" Optativa de primer ciclo de la titulación de Historia. Universidad de Valladolid.

I. Mesopotamia I. Condicionantes geográficos, antecedentes y bibliografía.

2. Mesopotamia II. Sumer. Del 3.500 al 539 a C.

3. Mesopotamia III. Asia Menor y los Hititas. Del 200 al 650 a C.
4. Egipto I. Introducción. Espacio natural, población y antecedentes.

5. Egipto II. La época predinástica. El imperio Antiguo hasta el segundo periodo intermedio.

6. Egipto III. El Imperio Nuevo, el tercer intermedio, la baja época.

\section{¿HACIA UN POSIBLE CONSENSO?}

Es posible pensar que es ventajoso el hecho de que el alumnado de cualquier Universidad pueda acceder a la Arqueología desde tan diversos puntos de vista. Sin embargo, en mi opinión, esta variedad no meditada ni pactada, al menos en el momento presente puede producir y produce confusión tanto dentro de las propias Universidades como, lo que es más importante, fuera de ellas, en nuestra sociedad. Por cuestiones laborales, profesionales y de imagen, nos conviene dar una idea bastante compacta de nuestra ciencia, nos conviene sin duda conseguir una titulación propia para la Arqueología y difícilmente se puede conseguir algo así cuando en el interior del mundo académico existe una variación tan profunda en cuanto a los conceptos.

En mi opinión, la Arqueología es la ciencia de la reconstrucción o representación de las culturas del pasado. Su objetivo no son objetos, sino procesos, no son cosas, sino culturas. Como ciencia, tiene su propio método -o sus métodos- y sus muchos procedimientos técnicos. Sirve a cualquier Historia, pero muy especialmente a la Historia como Antropología, es decir, a aquella que le importa el proceso y el cambio cultural más que los hechos aislados y aparentemente importantes.

En mi opinión también nadie puede llamarse Historiador o Historiadora prescindiendo de la Arqueología. En todo caso, se trataría de una Historia de los eventos registrados en la escritura, es decir, una Historia de hechos "importantes". Y a mí al menos lo que me importa del pasado no es eso, sino la forma de vivir que tuvo la gente que nos precedió.

Pero todo esto es "en mi opinión". De acuerdo con ella yo pienso en lo que debe contener un temario de "Arqueología" y lo establezco. A mi lado hay muchas personas que piensan de otra manera, totalmente distinta, y que lo establecen de otras formas.

No voy a promover una solución unilateral. Lo primero que hemos de hacer es asumir si esto es o no es un problema. Y si lo es, organicemos foros y debates para superarlo de la manera más consensuada posible. Si no lo es, adelante con esta algarabía.

\section{Instituto Latinoamericano de Museología. Universidad Nacional de Costa Rica}

Con una población aproximada de 400.000.000 de habitantes, América Latina tiene vínculos ecológicos, históricos y culturales que permiten considerarla una región mundial con idiosincrasia propia. Región que ha vivido y vive en varios de sus países situaciones adversas para el desarrollo humano, manifestándose estos procesos tanto en el uso que se hace del patrimonio natural, como en los testimonios de la dinámica cultural.

Una importante proporción de este patrimonio está administrado y custodiado por 3.000 museos y por más de 2.000 áreas naturales protegidas, tanto públicos como privados que abarcan la diversidad natural y cultural de la región.
La creciente necesidad, en todos los países del área latinoamericana de buscar y revitalizar sus raíces, de fortalecer su identidad cultural, y de salvaguardar sus recursos naturales, propiciando una mayor conciencia social, tanto a nivel regional como mundial, está provocando la constante creación de museos y parques, como un medio idóneo para coadyuvar a este fin.

Por esta razón su número ha mostrado un aumento considerable durante los últimos años, no así sus presupuestos ni su personal capacitado.

El establecimiento de áreas silvestres protegidas ha sido el paso más importante que han dado los países latinoamericanos para conservar la gran diversidad biológica que poseen. Sin embargo, estas áreas protegidas no podrán resistir la creciente presión que ejercen sobre ellas las poblaciones pobres que las rodean, si no proveen obvios beneficios económicos a la población. Estos beneficios deben ser al menos comparables a aquellos que esperarían obtener si se alterara el ecosistema natural para realizar actividades productivas (agricultura, explotación maderera, etc.)

Diversos países latinoamericanos han dado varios pasos a nivel local y nacional para "poner a trabajar" de manera sostenible las áreas protegidas y su biodiversidad en bien 